\title{
The association of maternal gestational diabetes mellitus with autism spectrum disorders in the offspring
}

\section{ABSTRACT}

Introduction. Some evidence exists for the association between exposure to pregestational maternal diabetes and risk of autism spectrum disorders (ASD) in offspring. Less information is available on the association of exposure to maternal gestational diabetes mellitus (GDM) with risk of ASD. We aimed to examine the prevalence of ASD disorders in offspring of mothers diagnosed with GDM.

Material and methods. We analyzed data gathered from GDM patients (947 women; 1007 children aged 4-16 years) treated at the Department of Metabolic Diseases, University Hospital in Krakow from 1999 to 2011. We conducted a telephone survey to collect clinical information and biochemical parameters. We performed significance test based on the exact binomial probability to assess if the prevalence rate of ASD in offspring of mothers with GDM was different from available epidemiological data for children aged 0-18 years in Poland. We also checked whether there are any significant factors discriminating the mothers and offspring with and without ASD.

Results. The prevalence of ASD in the offspring of mothers with GDM in our study (8/1007) was higher than in children aged 0-18 years in Poland (17.6/ /10 000; $p=0.0004)$. The mothers of children with ASD

Address for correspondence:

dr n. med. Elżbieta Kozek

Klinika Chorób Metabolicznych

Collegium Medicum Uniwersytetu Jagiellońskiego

ul. Kopernika 15, 31-501 Kraków

Phone: (+48) 124248305

Fax: (+48) 124219786

e-mail: ela_kozek@yahoo.com

Clinical Diabetology 2016, 5, 5, 147-151

DOI: $10.5603 /$ DK.2016.0026

Received: 12.10 .2016 had median pre-pregnancy BMI (20.862 vs. 23.529), SBP $(110 \mathrm{~mm} \mathrm{Hg}$ vs. $120 \mathrm{~mm} \mathrm{Hg})$ and DBP $(70 \mathrm{~mm} \mathrm{Hg}$ vs. $80 \mathrm{~mm} \mathrm{Hg}$ ) lower vs. group without ASD ( $p=0.0349$; $p=0.0149$ and $p=0.0306$ respectively). Birth weight of ASD children was significantly higher vs group without ASD (3695 g vs. 3320 g, p = 0.0482).

Conclusions. The prevalence of ASD seems to be higher in offspring of mothers with GDM than in the general population. Studying the potential risk factors is crucial for better understanding of this phenomenon and it may be helpful to preventi it. (Clin Diabetol 2016; 5, 5: 147-151)

Key words: metabolic diseases, epidemiology, gestational diabetes, autism spectrum disorders

\section{Introduction}

Maternal hyperglycemia is associated with increased risk of various undesirable fetal as well as children's outcomes occurring later in life. The list includes also neurological symptoms and diseases, for example neurodevelopmental delay, attention deficit hyperactivity disorder, learning difficulties or motor abnormalities [1].

Previous studies have shown some evidence of the association between exposure to pregestational maternal diabetes and risk of autism spectrum disorders (ASD) in the offspring [2-4]. It is less clear whether there is similar association between maternal gestational diabetes mellitus (GDM) and ASD in the offspring [5-8].

ASD, comprising of childhood autism, Asperger's disorder, atypical autism, pervasive developmental disorder non otherwise specified (PDD-NOS) and childhood disintegrative disorder, are characterized by deficits in functioning, social interactions and com- 
munications with repetitive and restricted patterns of behavior. The prevalence rate of ASD is rapidly growing, with estimated median of 65.5/10 000 and 61.9/ /10 000 in the North America and Europe respectively [9].

The current estimates in Poland are based on the registries of the National Health Fund with median of 17.6/10 000 children aged 0-18 years old [10]; older data from the former Krakow voivodeship from the group of six-year olds placed this prevalence at 6.2-9.6/10 000 [11].

The prevalence of ASD is rapidly growing; thus, studying the potential metabolic risk factors is crucial for better understanding of this phenomenon and may be helpful to prevent it. In our observational study, we aimed to assess the prevalence of ASD in the offspring of mothers diagnosed with GDM that were treated in the university clinic and compared it with the estimated prevalence of ASD in Poland in children aged $0-18$ years old.

\section{Methods}

We performed a retrospective, cross-sectional analysis of data gathered from GDM patients treated at the Department of Metabolic Diseases, University Hospital, a tertiary university center, Krakow, Poland from 1999 to 2011. 2372 GDM patients were included. Women with other types of diabetes were excluded. We managed to reach 947 mothers and 1007 children aged 4-16 years and obtain data by telephone or letter surveys, and by review of the patients' medical records.

We obtained numerous clinical (maternal educational level, parity, maternal and child's comorbidities, family history of ASD and diabetes, insulin treatment, type and week of delivery, maternal and child's age, week of GDM diagnosis, pre-pregnancy body mass index (BMI), highest BMI during pregnancy, weight gain during pregnancy, breastfeeding timespan, APGAR score, systolic and diastolic blood pressure (SBP and DBP respectively) and biochemical $\left(\mathrm{HbA}_{1 \mathrm{C}^{\prime}}\right.$ thyroid-stimulation hormone) parameters to compare the characteristics of women from ASD and non-ASD groups. Parameters such as: insulintreatment, maternal age, week of GDM diagnosis, pre-pregnancy BMI, highest $\mathrm{BMI}$ during pregnancy, weight gain during pregnancy, SBP, DBP, $\mathrm{HbA}_{1 \mathrm{c}^{\prime}}$ TSH were taken from the medical records.

The maternal and child's age calculation was performed on the 1st of January 2016; week of GDM diagnosis was taken from the medical records and defined as the time of the first recognition of hyperglycemia that was the basis of GDM diagnosis. GDM diagnosis was made using diagnostic criteria adequate for the 1999-2011 time period.
In Poland from 1999 to 2005 the diagnosis of GDM was based on a two-stage algorithm involving an oral glucose challenge test (GCT) with $50 \mathrm{~g}$ of glucose performed between $24^{\text {th }}$ and $28^{\text {th }}$ week of gestation. In case of an abnormal result [venous plasma glucose $>7.8 \mathrm{mmol} / \mathrm{l}(140 \mathrm{mg} / \mathrm{dl})$ after 60 minutes] it was followed by an oral glucose tolerance test (OGTT) with $75 \mathrm{~g}$ of glucose. GDM was diagnosed if fasting glucose was $>6.1 \mathrm{mmol} / \mathrm{l}(110 \mathrm{mg} / \mathrm{dl})$ or $>7.8 \mathrm{mmol} / \mathrm{l}$ $(140 \mathrm{mg} / \mathrm{dl}) 120$ minutes post-OGTT. From 2005 to 2011 a GCT with the cut-off of $7.8 \mathrm{mmol} / \mathrm{l}(140 \mathrm{mg} / \mathrm{dl})$ was not mandatory. Diagnosis of GDM was made if fasting glucose was $>5.6 \mathrm{mmol} / \mathrm{l}(100 \mathrm{mg} / \mathrm{dl})$ or if it was $>7.8 \mathrm{mmol} / \mathrm{l}(140 \mathrm{mg} / \mathrm{dl})$ in 120 minutes of $75 \mathrm{~g}$ OGTT $[12,13]$.

In the current study, children were considered to have an ASD based on interviews with mothers (the mothers were asked if a formal ASD diagnosis has been made).

To assess if the prevalence rate of ASD in the offspring of mothers with GDM was significantly different from available epidemiological data for children aged 0-18 years in Poland, we performed significance test based on the exact binomial probability.

To identify significant factors discriminating the mothers and offspring with and without ASD MannWhitney $\mathrm{U}$ test and Fisher's exact test were performed. STATISTICA 12 software, VassarStats.net and SocialScienceStatistics.com were used to analyze data. Statistical significance was defined as $p<0.05$.

The estimated median prevalence of ASD in children aged 0-18 years in Poland, diagnosed using ICD-10 criteria, based on the registries of the National Health Fund is 17.6/10 000 [10].

\section{Results}

The analysis included 947 mothers with GDM and 1007 children. There were 105 women $(4.4 \%$ out of 2372 subjects) that did not agree to participate in the telephone survey. Figure 1 shows the flow diagram for our study. We identified 8 cases of ASD, thus, the prevalence of ASD in the offspring of mothers with GDM patients in our study was $0.8 \%(8 / 1007)$, higher than in children aged $0-18$ years in Poland (17.6/ $/ 10000 ; p=0.0004$ ).

In the ASD group there were 2 cases of autistic disorder, 5 cases of Asperger's syndrome and 1 case of atypical autism. All affected children were male, the median age of diagnosis was 4.5 years and it ranged from 2.5 to 7 years.

In the group with ASD vs. group without ASD median pre-pregnancy BMI (20.862 vs. 23.529), SBP $(110 \mathrm{~mm} \mathrm{Hg}$ vs. $120 \mathrm{~mm} \mathrm{Hg})$ and DBP $(70 \mathrm{~mm} \mathrm{Hg}$ 


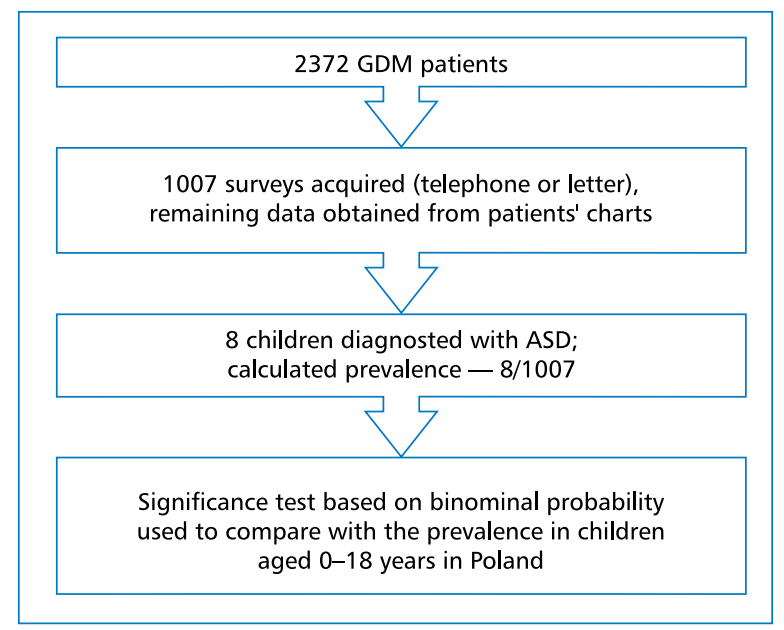

Figure 1. Study design flow. GDM - gestational diabetes mellitus; ASD - autism spectrum disorders

vs. $80 \mathrm{~mm} \mathrm{Hg})$ were $(\mathrm{p}=0.0349 ; \mathrm{p}=0.0149$ and $p=0.0306$ respectively) lower, whereas birth weight (3695 g vs. $3320 \mathrm{~g}$ ) was significantly $(\mathrm{p}=0.0482)$ higher.

For other parameters, comparative analysis of the obtained parameters showed no significant differences in educational level, parity, maternal hypertension, obesity, family history of diabetes, insulin administration, child's vaccinations according to the calendar, type of delivery, endangered pregnancy, age at the moment of conception, week of gestation when GDM was diagnosed, median highest BMI, weight gain during pregnancy, age when breastfeeding ceded, week of delivery, child's age, APGAR score, TSH and $\mathrm{HbA}_{1 \mathrm{c}}$ level. Table 1 shows in details results for all compared parameters.

\section{Discussion}

In this study we showed data providing further evidence for the association between maternal GDM and ASD in the offspring. This observation is in line with some previous data from pre-gestational and GDM [2-4, 14, 15].

Biological basis of the investigated phenomenon is not yet fully understood but some potential mechanisms have been identified. Firstly, maternal hyperglycemia can lead to fetal hypoxia and increase the oxidative stress, resulting in neurodevelopmental disorders [16-18]. Hyperglycemia can also enable epigenetic modifications [19]. Secondly, GDM is thought to induce chronic inflammation, which may be linked to the fact that ASD children have elevated levels of inflammatory biomarkers in the bloodstream [20]. Moreover, it is theorized that insulin-induced activation of PI3K/Tor kinase in neurons of the fetus could play some role, especially in the susceptible population [21].

In our study mothers of affected children had prepregnancy BMI within the normal range; however, it was lower than in the unaffected group. This contradicts earlier studies showing that mothers of ASD children were more likely to be obese [22]. The strong association of male sex and ASD [23] was confirmed in our study.

Already published data suggests that in retrospective analysis ASD children are more likely to have low body weight and to be small for gestational age but maternal GDM was not considered in this analysis [5]. In our whole study group the birthweight of boys was significantly higher than the girls. This and the fact that all ASD children were males may contribute to the difference in birthweight between ASD and non-ASD children.

Concerning the fact that in our study SBP and DBP were significantly lower in the non-ASD group we believe that this result is clinically meaningless because in both subgroups the median values were within the normal range. Of note, all hypertensive mothers were in the non-ASD group.

We identified some shortcomings of our study. Due to the lack of access to the data of non-GDM mothers, we were unable to form a control group and asses the prevalence of ASD in it. Instead, we used the best available epidemiological data on the prevalence of ASD in all children aged 0-18 years in Poland that uses ICD-10 criteria [10]. A small number of patients in the ASD group results from low prevalence of ASD in the general population. We did not have an access to the criteria used to diagnose ASD in the offspring. We admit that our study design may have had impact on the results. Contrary to some of the previous studies, we did not access the data of ASD children, but instead relied on the medical records and surveys gathered from GDM mothers. Additionally, some number of women refused to participate in the study, what could have introduced some bias, as for example those with children affected by ASD were more likely not to respond.

We believe that our study has also some strengths. The mothers of affected children in our study were not obese or hypertensive - lack of other already identified risk factors for the ASD in our opinion increases the reliability of our finding that GDM increases the risk of ASD. Moreover, our study group was relatively large for one-center survey-based study. In general, there is a lack of such epidemiological research in Poland, including the field of ASD. The available information of the prevalence of ASD in Poland is based on the registries that incorporate reported data from health 
Table 1. Clinical characteristics of the study groups. Women with gestational diabetes mellitus (GDM) diagnosis having children with autism spectrum disorders (ASD) and the rest of the study group

\begin{tabular}{|c|c|c|c|c|c|}
\hline \multirow{2}{*}{$\begin{array}{l}\text { Characteristic } \\
\text { Socioeconomic status }\end{array}$} & \multicolumn{2}{|c|}{ ASD } & \multicolumn{2}{|c|}{ Non-ASD } & \multirow{2}{*}{$\frac{\text { ASD vs. non-ASD }}{p}$} \\
\hline & $\mathbf{n}$ & $\%$ & $\mathbf{n}$ & $\%$ & \\
\hline Education & & & & & 0.4002 \\
\hline Primary & 0 & 0 & 18 & 1.83 & \\
\hline Vocational & 0 & 0 & 103 & 10.45 & \\
\hline Secondary & 1 & 12.5 & 292 & 29.61 & \\
\hline Higher & 7 & 87.5 & 573 & 58.11 & \\
\hline Multipara & 5 & 62.5 & 545 & 55.05 & 0.7368 \\
\hline Diabetes in the family history & 7 & 87.5 & 511 & 51.88 & 0.0712 \\
\hline Maternal characteristics & n & $\%$ & n & $\%$ & p \\
\hline Insulin treatment & 6 & 75 & 578 & 58.38 & 0.4808 \\
\hline Maternal hypertension & 0 & 0 & 126 & 12.61 & 0.6057 \\
\hline \multirow[t]{2}{*}{ Obesity } & 0 & 0 & 143 & 14.79 & 0.3799 \\
\hline & Median & & Median & & $\mathrm{p}$ \\
\hline Age at the moment of conception (year) & 29.5 & & 30 & & 0.3382 \\
\hline Median BMI before pregnancy $\left[\mathrm{kg} / \mathrm{m}^{2}\right]$ & 20.862 & & 23.529 & & $0.0349 *$ \\
\hline Median highest BMI during pregnancy $\left[\mathrm{kg} / \mathrm{m}^{2}\right]$ & 26.502 & & 28.04 & & 0.1904 \\
\hline Weight gain during pregnancy $[\mathrm{kg}]$ & 12.8 & & 11.8 & & 0.3733 \\
\hline Week of gestation when GDM was diagnosed (week) & 29 & & 27 & & 0.1905 \\
\hline Age when breastfeeding ceded (month) & 9 & & 6 & & 0.5117 \\
\hline $\mathrm{SBP}[\mathrm{mm} \mathrm{Hg}]$ & 110 & & 120 & & $0.0149^{*}$ \\
\hline $\mathrm{DBP}[\mathrm{mm} \mathrm{Hg}]$ & 70 & & 80 & & $0.0306^{*}$ \\
\hline $\mathrm{TSH}[\mathrm{uUI} / \mathrm{ml}]$ & 1.216 & & 1.310 & & 0.7636 \\
\hline $\mathrm{HbA}_{1 \mathrm{c}}(\%)$ & 4.9 & & 5.2 & & 0.0695 \\
\hline Pregnancy outcomes & $\mathrm{n}$ & $\%$ & $\mathrm{n}$ & $\%$ & $\mathbf{p}$ \\
\hline Cesarean section & 5 & 62.5 & 420 & 42.42 & 0.2964 \\
\hline \multirow[t]{2}{*}{ Endangered pregnancy \# } & 1 & 12.5 & 53 & 5.61 & 0.3576 \\
\hline & Median & & Median & & $\mathrm{p}$ \\
\hline Week of delivery (week) & 40 & & 39 & & 0.1186 \\
\hline Child outcomes & n & $\%$ & n & $\%$ & $\mathbf{p}$ \\
\hline Child's gender, male & 8 & 100 & 534 & 53.51 & $0.0089^{*}$ \\
\hline \multirow[t]{2}{*}{ Child's vaccination according to the calendar } & 7 & 87.5 & 984 & 98.7 & 0.1065 \\
\hline & Median & & Median & & p \\
\hline Child's age (year) & 8 & & 7 & & 0.1043 \\
\hline APGAR score & 10 & & 10 & & 0.7596 \\
\hline Birth weight $[g]$ & 3695 & & 3320 & & $0.0482 *$ \\
\hline
\end{tabular}

* - result is significant at $\mathrm{p}<0.05 ;{ }^{\#}$ - category includes: preeclampsia, eclampsia and reported by mother premature onset of delivery (i.e. early contractions)

centers. To find the most reliable information on the prevalence of ASD in Poland we conducted search in multiple databases and the only study on the subject that assessed the prevalence using surveys and medical examination was published in the 2003 and was limited only to 6 -year-olds [11]. The fact that, besides our study, we only found one that did not use registries to assess the prevalence rate of ASD in Poland, makes the subject highly under researched and calls for wider attention.

\section{Conclusions}

The prevalence of ASD in the offspring of mothers with GDM in our study was significantly higher than in children aged 0-18 years from the general population 
of Poland. That adds to the already published research that there is evidence for association between maternal GDM and increased risk of ASD in the offspring.

\section{Acknowledgements}

We would like to thank the Department of Metabolic Diseases, Jagiellonian University Medical School for enabling us to conduct our study by giving access to the medical records of the patients.

\section{Conflict of interest}

We declare no conflict of interest.

\section{REFERENCES}

1. Ornoy A, Reece EA, Pavlinkova G et al. Effect of maternal diabetes on the embryo, fetus, and children: congenital anomalies, genetic and epigenetic changes and developmental outcomes. Birth Defects Research (Part C) 2015; 105: 53-72.

2. Xiang $A H$, Wang $X$, Martinez MP et al. Association of maternal diabetes with autism in offspring. JAMA 2015; 313: 1425-1434.

3. Xu G, Jing J, Bowers $\mathrm{K}$ et al. Maternal diabetes and the risk of autism spectrum disorders in the offspring: a systematic review and meta-analysis. J Autism Dev Disord 2014; 44: 766-775.

4. Li M, Fallin MD, Riley A et al. The Association of maternal obesity and diabetes with autism and other developmental disabilities. Pediatrics 2016; 137: 1-10.

5. Guinchat $\mathrm{V}$, Thorsen $\mathrm{P}$, Laurent $\mathrm{C}$ et al. Pre-, peri- and neonatal risk factors for autism. Acta Obstet Gynecol Scand 2012; 91: 287-300.

6. Gardener H, Spiegelman D, Buka SL. Prenatal risk factors for autism: comprehensive meta-analysis. Br J Psychiatry 2009; 195: 7-14.

7. Dodds $L$, Fell DB, Sheaet $S$ et al. The role of prenatal, obstetric and neonatal factors in the development of autism. J Autism Dev Disord.2011; 41: 891-902.

8. Mamidala MP, Polinedi A, Praveen Kumar PTV et al. Prenatal, perinatal and neonatal risk factors of Autism Spectrum Disorder: a comprehensive epidemiological assessment from India. Res Dev Disabil 2013; 34: 3004-3013.
9. Elsabbagh M, Divan G, Koh Y-J et al. Global prevalence of autism and other pervasive developmental disorders. Autism Res 2012; 5: 160-179.

10. Piskorz-Ogórek K, Ogórek S, Cieślińska A, Kostyra E. Autism in Poland in comparison to other countries. Polish Annals of Medicine 2015; 22: 35-40.

11. Jaklewicz H, Mackiewicz R, Gardziel A, Kosk J. Comparative study on the incidence of autistic disorders in Poland and in France. Psychiatr Psychol Klin 2003; 3: 232-239.

12. Zalecenia Zespołu Ekspertów do spraw wczesnego rozpoznawania cukrzycy w ciąży, powołanego przez Polskie Towarzystwo Diabetologiczne. Diabetologia Pol 1994; 1: 80-81.

13. Zalecenia kliniczne dotyczące postępowania u chorych na cukrzycę 2005. Stanowisko Polskiego Towarzystwa Diabetologicznego. Diabetol Prakt 2004 (Suppl D): 1-36.

14. Nahum Sacks K, Friger M, Shoham-Vardi I et al. Prenatal exposure to gestational diabetes mellitus as an independent risk factor for long-term neuropsychiatric morbidity of the offspring. Am J Obstet Gynecol 2016; 215: 380.e1-e7.

15. Ornoy A, Weinstein-Fudim L, Ergaz Z. Prenatal factors associated with autism spectrum disorder (ASD). Reproductive Toxicology 2015; 15; 56: 155-169.

16. Eidelman Al, Samueloff A. The pathophysiology of the fetus of the diabetic mother. Seminars in Perinatology 2002; 26: 232-236.

17. Burstyn I, Wang $X$, Yasui $Y$ et al. Autism spectrum disorders and fetal hypoxia in a population-based cohort: accounting for missing exposures via Estimation-Maximization algorithm. BMC Medical Research Methodology 2011; 11: 2.

18. Chauhan A, Chauhan V, Brown WT, Cohen I. Oxidative stress in autism: increased lipid peroxidation and reduced serum levels of ceruloplasmin and transferrin-the antioxidant proteins. Life Sciences 2004; 75: 2539-2549.

19. Fernandez-Morera JL, Rodriguez-Rodero S, Menendez-Torre $E_{\text {, }}$ Fraga MF. The possible role of epigenetics in gestational diabetes: Cause, consequence, or both. Obstetrics and Gynecology International 2010; 2010: 605163.

20. Onore C, Careaga M, Ashwood P. The role of immune dysfunction in the pathophysiology of autism. Brain, Behavior, and Immunity 2012; 26: 383-392.

21. Stern M. Insulin signaling and autism. Frontiers in Endocrinology 2011; 2: 54.

22. Connolly N, Anixt J, Manning P et al. Maternal metabolic risk factors for autism spectrum disorder-An analysis of electronic medical records and linked birth data. International Society for Autism Research 2016; 9: 829-837.

23. Fombonne E. Epidemiology of pervasive developmental disorders. Pediatric Research 2009; 65: 591-598. 